\title{
KESADARAN LINGKUNGAN DI TENGAH PANDEMI COVID-19 DALAM FILM DIAM DAN DENGARKAN
}

\section{ENVIRONMENTAL AWARENESS AMID THE COVID-19 PANDEMIC IN SILENT AND LISTEN MOVIES}

\author{
Mayadasari $^{1^{*}}$, Firdaus Yuni Dharta ${ }^{2}$, Muhammad Ramdhani. \\ ${ }^{123}$ Program Studi Ilmu Komunikasi, Fakultas Ilmu Sosial dan Ilmu Politik, Universitas Singaperbangsa \\ Karawang, Jalan H.S Ronggowaluyo, Kecamatan Telukjambe Timur, Kabupaten Karawang, 41361 \\ *Korespondensi: Mayadasari, Email: maya.mayadasari17015@student.unsika.ac.id
}

(Diterima oleh Dewan Redaksi: 26-07-2021)

(Dipublikasikan oleh Dewan Redaksi: 15-10-2021)

\begin{abstract}
Environmental awareness is the thought of a person or group that is manifested in an attitude that supports nature conservation. Without awareness to protect the environment, natural conditions will continue to be alarming. Seeing the current state of the environment, producer Mahatma Putra used this opportunity to make a documentary film "Silence and Listen" which describes various facts about the impacts of everyday human activities that damage the environment. The purpose of this study was to determine the meaning of environmental awareness in the midst of the covid-19 pandemic in the film Silent and Listen with qualitative methods and Roland Barthes semiotic analysis. Data collection techniques through observation, documentation and literature study. The main problem of this research refers to the delivery of environmental awareness messages in the documentary Silent and Listen. The result is that the meaning of environmental awareness in the midst of the covid-19 pandemic is not conveyed directly, but through dialogue and pictures that show environmental damage caused by people's daily activities that are not realized, such as water pollution by foam, the views of rural communities on the concept of refrigerators, and the Covid-19 pandemic has given pause for the earth to speak through its self-quarantine policy.
\end{abstract}

Keywords: Film; Semiotics; Enviromental Awareness.

\begin{abstract}
ABSTRAK
Kesadaran lingkungan adalah pemikiran seseorang atau kelompok yang terwujud dalam sikap yang mendukung pelestarian alam. Tanpa kesadaran untuk menjaga lingkungan, kondisi alam akan terus memprihatinkan. Melihat keadaan lingkungan saat ini, produser Mahatma Putra menggunakan peluang ini untuk membuat film dokumenter "Diam dan Dengarkan" yang memaparkan berbagai fakta dampakdampak aktivitas manusia sehari-hari yang merusak lingkungan. Tujuan dari penelitian ini untuk mengetahui makna kesadaran lingkungan di tengah pandemi covid-19 dalam film Diam dan Dengarkan dengan metode kualitatif dan analisis semiotika Roland Barthes. Teknik pengumpulan data melalui observasi, dokumentasi dan studi pustaka. Pokok permasalahan dari penelitian ini mengacu pada penyampaian pesan kesadaran lingkungan dalam film dokumenter Diam dan Dengarkan. Adapun hasilnya yaitu, makna kesadaran lingkungan di tengah pandemi covid-19 tidak disampaikan langsung, melainkan melalui dialog dan gambar yang memperlihatkan kerusakan lingkungan diakibatkan oleh aktivitas masyarakat sehari-hari yang tidak disadari, seperti polusi air oleh busa, pandangan masyarakat pedalaman tentang konsep kulkas, serta pandemi covid-19 memberi jeda untuk bumi berbicara melalui kebijakan karantina mandiri.
\end{abstract}

Kata Kunci: Film; Semiotika; Kesadaran Lingkungan.

Mayadasari, 2021. Kesadaran Lingkungan Di Tengah Pandemi Covid-19 Dalam Film Diam dan Dengarkan. 


\section{PENDAHULUAN}

Keadaan lingkungan saat ini berada dalam kondisi yang sangat memprihatinkan. Pemanasan global, polusi udara, pembukaan lahan baru yang menggerus habis hutan, pencemaran sungai, kepunahan hewan langka sampai keberadaan sampah yang hampir ada di setiap sudut bumi. Semua itu diakibatkan oleh manusia yang kurang bijak dalam memilih aktivitasnya. Seperti yang dikatakan Andien Aisyah dalam Film dokumenter Diam dan Dengarkan, makin tinggi kesejahteraan manusia, semakin meningkat pula konsumsi, jejak karbon, dan kerusakan lingkungan yang diciptakannya (Merdeka, 2020).

Melihat keadaan lingkungan yang sudah berada dalam ambang kerusakan ini, muncul gerakan peduli terhadap lingkungan. Salah satunya dengan kampanye menggunakan media massa melalui film. Film merupakan salah satu media massa yang berkembang pesat. Hal ini berkaitan dengan isi pesan yang disampaikan merupakan refleksi dari realitas yang berkembang di masyarakat (Sobur, 2013). Salah satu jenis film yang merefleksikan mengenai realitas yakni film dokumenter.

Penelitian Fitri (2020) membahas mengenai pesan kampanye lingkungan dalam film Sexy Killer. Hasil dari penelitian tersebut, terdapat perbedaan penerimaan pesan yang diterima khalayak dalam mempresentasikan arti kerusakan lingkungan dalam film tersebut. Terlebih, film dokumenter Sexy Killer garapan Dandy Laksono sempat menyedot perhatian masyarakat. Isu mengenai bisnis pertambangan batu bara yang merusak lingkungan tanah borneo juga menyeret nama-nama pemimpin di pemerintahan Indonesia tampaknya menarik perhatian massa. Akan tetapi, isu lingkungan tersebut masih awam untuk masyarakat, karena dampak dari kerusakan hasil pertambangan tidak dirasakan langsung oleh masyarakat luas.

Berbeda halnya dengan isu lingkungan yang dibahas oleh penelitian ini yang dikemas oleh rumah produksi Anatmant Pictures melalui film dokumenter Diam dan Dengarkan. Dirilis saat Juni 2020 dimana pandemi covid-19 masih mengukung dunia, film ini menarik untuk diteliti. Film Diam dan Dengarkan mencoba memberikan perenungan kesadaran lingkungan bagi khalayak dengan tagline film-nya "Pandemi Jeda untuk Bumi". Dalam film ini, membahas mengenai kegiatan-kegiatan manusia sehari-hari yang ternyata tanpa kita sadari berdampak pada lingkungan. Seperti penggunaan sampah plastik, penggunaan sabun SLS (Sodium Lauryl Sulfate) terhadap keberadaan air bersih, cara pandang orang hutan dengan orang kota, kesehatan mental, hingga kekuasaan uang terhadap keputusan kegiatan manusia yang berdampak pada lingkungan.

Hal-hal diatas merupakan kegiatan sehari-hari yang biasa dilakukan manusia kebanyakan. Namun tanpa disadari, kegiatan tersebut juga menjadi penyumbang kerusakan lingkungan. Bukan hanya soal perusahaan nakal yang membuang limbah sembarang, pembukaan lahan baru untuk sawit yang menggerus hutan dan juga aktivitas pertambangan yang menimbulkan banyak permasalahan. Tetapi juga kerusakan lingkungan yang terjadi akibat aktivitas - aktivitas yang dilakukan individu sehari-hari.

Berdasarkan isu keadaan lingkungan yang dikemas melalui film Diam dan Dengarkan, penelitian mengenai makna keasadaran lingkungan yang disampaikan dalam film tersebut menarik untuk diteliti. Peneliti tertarik menelaah bagaimana makna denotasi, konotasi dan mitos kesadaran lingkungan yang terdapat dalam film Diam dan Dengarkan dengan 
menggunakan metode penelitian kualitatif dan paradigma kritis.

\section{MATERI DAN METODE}

\section{MATERI}

Komunikasi Massa

Komunikasi massa adalah proses komunikasi yang disampaikan melalui media massa dan ditujukan untuk massa/khalayak. Dalam buku Burhan Bungin, komunikasi massa diartikan sebagai proses komunikasi yang dilakukan melalui media massa dengan berbagai tujuan komunikasi dan untuk menyampaikan informasi kepada khalayak luas (Bungin, 2006). Adapun unsur-unsur penting dalam komunikasi massa diantaranya, komunikator, media massa, informasi massa, gatekeeper, khalayak/publik, dan umpan balik (Bungin, 2006). Melihat dari unsur-unsur tersebut disinyalir membuat komunikasi massa, mempermudah

individu/kelompok/organisasi untuk menyebarkan informasi melalui kehadiran media massa yang ditujukan untuk khalayak luas dalam jumlah banyak dengan waktu yang cepat.

Media massa merupakan media komunikasi dan informasi yang tersebar secara luas dan dapat diakses oleh khalayak. Media yang terdapat dalam media massa diantara televisi, radio, surat kabar, serta film sebagai media komunikasi massa. Film memiliki kekuatan serta pengaruh besar dalam menjangkau banyak segmen sosial.

\section{Film}

Film merupakan salah satu media massa yang berkembang pesat. Hal ini berkaitan dengan isi pesan yang disampaikan merupakan refleksi dari realitas yang berkembang di masyarakat (Sobur, 2013). Salah satu jenis film yang merefleksikan mengenai realitas yakni film dokumenter. Menurut Kamus Besar Bahasa Indonesia (KBBI), Film dokumenter merupakan dokumentasi dalam bentuk film mengenai suatu peristiwa bersejarah atau suatu aspek seni budaya yang mempunyai makna khusus agar dapat menjadi alat penerangan dan alat pendidikan. Perbedaan dari filmfilm yang memiliki unsur seni dengan film dokumenter sendiri yakni pada nilai kebenaran dan faktualnya.

Mengacu pada pengertian film dokumenter diatas, banyak para filmmaker dan aktivisaktivis lingkungan yang menggunakan film sebagai media menyampaikan pesan mengenai keadaan dan kesadaran lingkungan.

\section{Kesadaran Lingkungan}

Adapun Kesadaran lingkungan adalah sebuah konstruk multidimensi yang terdiri dari komponen kognitif, sikap, dan perilaku (Schlegelmilch et al, 1996). Komponen kognitif tersebut terdiri dari pengetahuan lingkungan yang dimiliki seseorang, menyangkut isu-isu lingkungan yang sedang terjadi. Lalu sikap didasarkan atas sikap atau perilaku seseorang terhadap lingkungan, seperti kepedulian atau acuhnya seseorang terhadap keadaan lingkungan.

Seperti yang kita ketahui, gerakan kesadaran lingkungan di tengah-tengah masyarakat selama beberapa dekade terakhir semakin meningkat. Peningkatan ini dicetus oleh adanya kekhawatiran dengan keadaan bumi yang semakin memburuk. Pemanasan global, penipisan lapisan ozon, hujan asam, hingga polusi udara, suara serta tanah, penggundulan hutan, hilangnya daerah serapan air akibat pembangunan, sampah yang menggunung, menjadi momok yang menakutkan untuk keberlangsungan makhluk hidup di bumi.

Dapat disimpulkan, kesadaran lingkungan adalah sebuah usaha untuk menjaga lingkungan agar tercipta lingkungan yang sehat dan terhindar dari bencana alam yang diakibatkan oleh kerusakan bumi akibat ulah manusia itu sendiri. Menurut Daniel Chiras (Neolaka, 2008), dasar dari penyebab lingkungan adalah etika lingkungan. Etika lingkungan yang berlaku 
saat ini didasarkan pada sistem nilai yang mendudukan manusia bukan bagian dari alam, tetapi manusia sebagai penakluk dan pengatur alam.

\section{METODE PENELITIAN}

Film erat kaitannya dengan kajian semiotika. Menurut Preminger, semiotika adalah ilmu tentang tanda-tanda. Ilmu yang menganggap bahwa fenomena sosial/masyarakat dan kebudayaan itu merupakan tanda-tanda. Dalam semiotik, mempelajari sistem-sistem, aturan-aturan, konvensi-konvensi yang memungkinkan tanda-tanda tersebut memiliki arti.

Kaitannya dengan sosial dan budaya, semiotika digunakan untuk mempelajari sederetan peristiwa yang berada di masyarakat sebagai sebuah tanda yang memiliki arti tertentu. Konsep dasar dari semiotik ada dua, yang pertama tanda yang memiliki stimulus yang menandakan atau menunjukan beberapa kondisi, contohnya ketika ada asap menandakan adanya api. Konsep dasar kedua adalah simbol, biasa menandakan tanda yang kompleks dengan banyak arti yang sangat khusus (Littlejhon, Karen A. Foss, 2018).

Adapun dalam penelitian ini menggunakan metode penelitian kualitatif dengan analisis semiotika Roland Barthes. Metode penelitian kualitatif berlandaskan pada filsafat post positivisme, yakni digunakan untuk meneliti objek alamiah, dimana peneliti sebagai instrumen kunci, teknik pengumpulan data dapat dilakukan gabungan, analisis data bersifat induktif, dan hasil penelitian kualitatif lebih menekankan makna dibandingkan generalisasinya (Sugiyono, 2014).

Teori semiotika Roland Barthes secara harfiah diturunkan dari teori bahasa menurut de Saussure. Menurut Barthes, bahasa adalah suatu sistem tanda yang mencerminkan asumsi-asumsi dari masyarakat tertentu dalam waktu tertentu (Sobur, 2013).

Dalam teori Roland Barthes, mengemukakan dua tingkatan pertanda, yaitu denotasi dan konotasi. Denotasi menurut pandangan Barthes adalah tataran pertama yang maknanya bersifat tertutup. Tataran denotasi menghasilkan hubungan eksplisit antara tanda dengan referensi atau realitas dalam pertandaan. Sedangkan konotasi yaitu tanda dimana berkaitan antara perasaan dan emosi serta nilai-nilai kebudayaan dan ideologi.

Konotasi diidentikan dengan operasi ideologi, yang disebut sebagai "mitos". Menurut Barthes, mitos adalah perkembangan dari konotasi. Konotasi yang sudah terbentuklama di masyarakat itu lah mitos (Vera, 2014). Mitos dibangun sebagai suaturantai pemaknaan yang sudah ada sebelumnya atau dengan kata lain sebagai sistem pemaknaan tataran kedua. Mitos berfungsi untuk mengungkapkan dan memberikan pembenaran bagi nilai-nilai dominan yang berlaku dalam suatu periode tertentu. Sedangkan, dalam mitos juga terdapat pola tiga dimensi penanda, petanda, dan tanda, namun sebagai sistem yang unik.

Adapun Roland Barthes menyusun peta tentang bagaimana sebuah tanda bekerja (Cobley \& Jansz,1999:51).

Tabel 1 Peta Roland Barthes

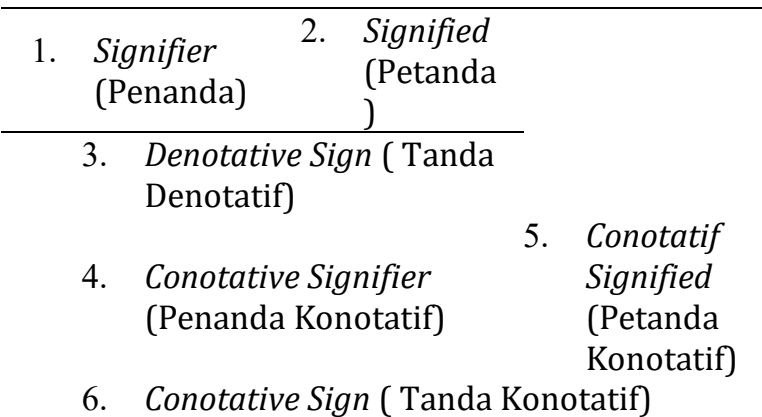

Sumber : Sobur, 2006

Dari tabel di atas dijelaskan bahwa Denotative Sign/tanda denotatif (3) secara bersamaan terdiri atas penanda (1) dan (2), juga berfungsi sebagai penanda konotatif (4). Dengan kata lain, hal tersebut merupakan unsur material, misalkan kita mengenal tanda "Kancil", maka konotasinya mungkin saja cerdik, tangkas, atau licik. Maka dari itu, sumbangan Roland Barthes sangat berarti bagi penyempurnaan semiologi Saussure 
mengenai tanda konotatif. Bukan hanya sekedar memiliki makna tambahan, tetapi juga mengandung kedua bagian tanda denotatif yang melandasi keberadaannya. Perspektif Barthes tentang mitos juga menjadi ciri khas semiologinya sehingga membuka ranah baru.

Paradigma yang digunakan dalam penelitian ini menggunakan paradigma kritis. Karena fokus paradigma ini lebih kepada pengungkapan dan analisis sosial dengan mempertanyakan kesenjangan relasi sosial yang ada karena menyatukan teori dan praktik/tindakan. Teori yang dimaksud bersifat berpegang teguh akan norma atau nilai yang seharusnya dapat digunakan di kehidupan bermasyarakat agar mendorong terjadinya perubahan yang lebih baik (Halik, 2018). Oleh karena itu, penelitian ini menggunakan paradigma kritis agar realitas mengenai makna kesadaran lingkungan di tengah pandemi covid-19 dalam film Diam dan Dengarkan dapat diungkapkan melalui simbol, visual video atau gambar yang berkaitan dan makna yang terkandung dapat membawa perubahan yang lebih baik untuk masyarakat Indonesia.

Sumber data dalam penelitian terdiri dari data primer dan data sekunder. Data primer yang digunakan yakni rekaman video dalam film dokumenter Diam dan Dengarkan yang dapat ditonton melalui kanal Youtube resmi Anatmant Pictures. Dimana dalam film ini terdapat makna kesadaran lingkungan di tengah pandemi covid-19 melalui narasi atau gambar/video yang digambarkan dalam film tersebut. Data sekunder diperoleh melalui publikasi, studi literatur dan informasi yang didapat dari jurnal atau artikel, buku, majalah maupun website resmi di internet mengenai kesadaran lingkungan di tengah pandemi covid-19.

Fokus penelitian ini menelaah makna kesadaran lingkungan dalam film Diam dan Dengarkan, sehingga tidak memerlukan informan untuk melakukan wawancara. Berikut teknik-teknik yang digunakan dalam penelitian ini yang pertama observasi. Dalam observasi, teknik pengumpulan data yang mengharuskan peneliti turun langsung mengamati hal-hal yang berkaitan dengan objek penelitian (Ghony, 2016). Peneliti akan melakukan observasi terhadap visual dalam video, dialog, gambar yang menunjukan makna kesadaran lingkungan dalam Film Diam dan Dengarkan. Yang kedua, dokumentasi. Peneliti akan mendokumentasikan dengan screenshot pada adegan/scene yang memiliki simbol atau tanda makna kesadaran lingkungan dalam film Diam dan Dengarkan. Dan yang terakhir, studi pustaka, hal ini guna melengkapi bahan dan data penelitian, peneliti akan mencari datadata melalui sumber-sumber tertulis mengenai objek penelitian ini. Sehingga dalam penelitian ini dapat diperoleh data yang kuat. Studi pustaka yang digunakan berupa jurnal-jurnal, buku, situs web yang berkaitan dengan penelitian ini.

\section{HASIL DAN PEMBAHASAN}

\section{HASIL DAN PEMBAHASAN}

\section{Hasil Penelitian}

Diam dan Dengarkan merupakan sebuah film dokumenter di tengah pandemi karya Mahatma Putra melalui rumah produksi Anatman Pictures yang dirilis pada bulan Juni 2020. Dengan menggandeng beberapa aktivis lingkungan, fashion designer, ahli lingkungan, public figure, ahli kesehatan holistik, tokoh agama, hingga pemilik bisnis, film dokumenter ini memaparkan isu-isu kerusakan lingkungan akibat dari aktivitas manusia sehari-hari yang tidak disadari ikut menyumbang kerusakan bagi alam. Dalam penyajiannya, film ini menggunakan gaya penyutradaraan expository, menekankan narasi dalam penyampaian pesannya dan mengajak penonton untuk merenungkan nasib alam melalui tagline "Pandemi Jeda untuk bumi". Dari rangkaian analisis yang telah dilakukan, berikut penyajian data terkait makna denotasi, konotasi dan mitos 
kesadaran lingkungan dalam Film Diam dan Dengarkan.

\section{Tabel 2 Sajian Data Makna Kesadaran Lingkungan Film Diam dan Dengarkan}

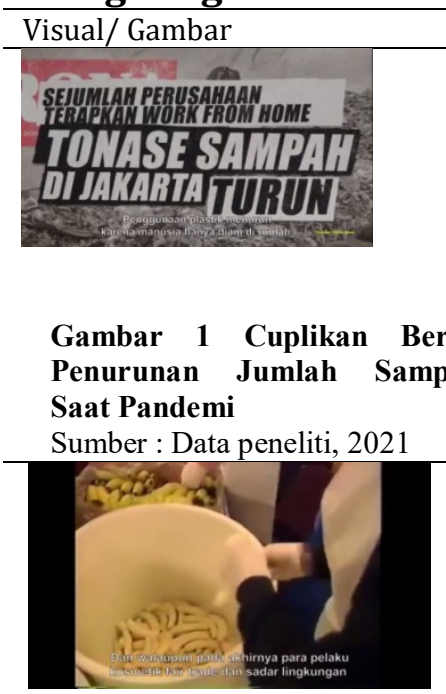

Gambar 2 Cupilkan Pembuatan Sampo dari Pisang Sumber : Data Peneliti, 2021

"Pialog

manusia mengambil jarak dengan sesama, juga dengan plastik. Penggunaan plastik menurun karena manusia hanya diam di rumah" (Dennis

Adiswara)

"Kesadaran tentang kosmetik fair trade dan ramah lingkungan sudah dimulai sejak tahun 70-an, dan walaupun pada akhirnya para pelaku kosmetik fair trade dan sadar lingkungan terus tergilas roda industri. Jejak perjuangan kosmetik ramah lingkungan terus tumbuh." (Eva Cellia)

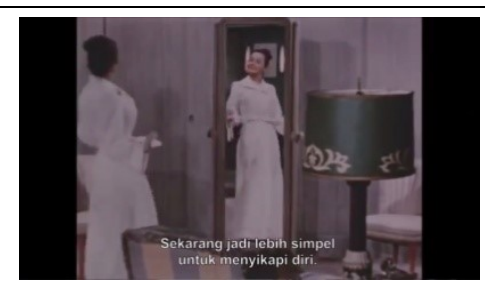

"Pandemi yang terjadi membawa orang mengubah prioritas hidup. Kita jadi lebih sering mementingkan apa yang kita pikirkan. Sekarang lebih simple untuk menyikapi diri" Gambar 3 Cuplikan Wanita (Didiet Maulana) tengah bercermin Sumber : Data Peneliti, 2021

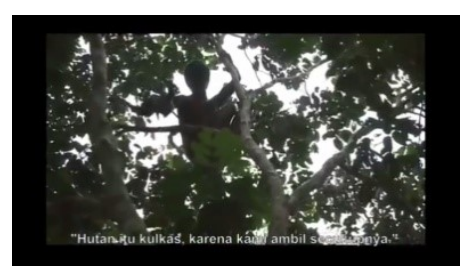

Gambar 4 Cuplikan Orang Hutan yang tengah mengambil buah di pohon

Sumber : Data Peneliti, 2021

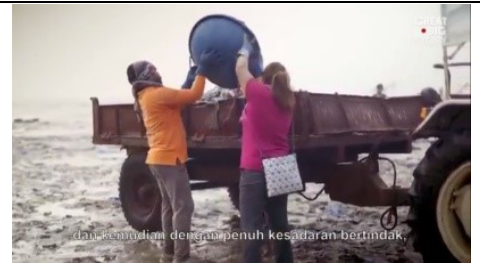

Gambar 5 Cuplikan dua orang tengah membuang sampah ke mobil bak

Sumber : Data Peneliti, 2021

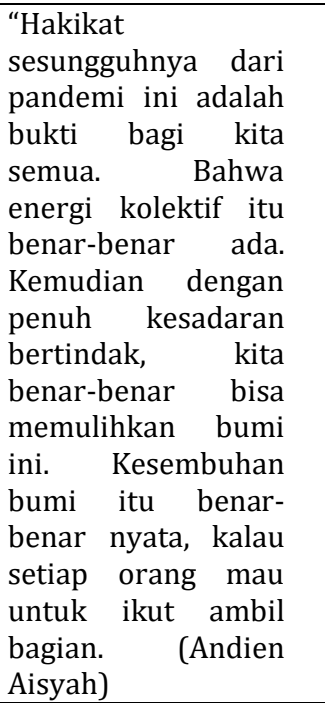

Sumber : Data Peneliti, 2021

\section{Makna Denotasi, Konotasi dan Mitos Kesadaran Lingkungan Di Tengah Pandemi Covid-19}

Makna denotasi kesadaran lingkungan dalam film disajikan melalui pesan-pesan yang disampaikan oleh narator dan narasumber dengan gaya penyutradaraan expository. Gambar dan video yang dikemas menggunakan lisensi Creative Common yangmana diambil dari berbagai sumber bukan milik rumah produksi. Hal ini juga berkaitan dengan proses produksi yang mengikuti kebijakan karantina mandiri Pemerintah RI saat pandemi melanda (Merdeka, 2020). Penggunaan gambar atau video yang dilisensikan membuat pemaknaan dalam film ini luas dari berbagai sudut pandang, karena terdapat gambar atau video yang memperlihatkan keadaan lingkungan sejak zaman pra-sejarah hingga modern saat ini. Sehingga menjadi pengingat bagi penonton bahwa dari masa ke masa kerusakan lingkungan terus terjadi.

Adapun pesan kesadaran lingkungan dalam film disampaikan dengan cara memperlihatkan dahulu bagaimana kerusakan lingkungan akibat aktivitas manusia sehari-hari yang tidak disadari. Kemudian tersirat makna tersembunyi yang secara khusus menyadarkan penonton untuk sadar merawat lingkungan dimulai dari bijak dalam memilih aktivitas sehari-hari yang lebih ramah lingkungan. 
Pesan tersebut juga diyakinkan dengan hadirnya narasumber dari berbagai profesi, seperti aktivis lingkungan, enviromental scientis, ahli kesehatan holistik, Fashion Designer, pemilik bisnis, tokoh agama, budayawan, hingga public figure yang aware dengan lingkungan.

Lalu makna konotasi kesadaran lingkungan dalam film ini diperlihatkan dari bagaimana serakahnya manusia yang memiliki ilmu pengetahuan lebih namun merusak lingkungan yang ada. Dan kerusakan itu berdampak balik merugikan manusia itu sendiri. Usai mendapatkan kerugian bagi dirinya, manusia baru sadar bahwa menjaga lingkungan itu penting. Melalui pandemi dimana aktivitas manusia sejenak terhenti, memberi perenungan bahwa alam perlu istirahat dari hiruk pikuk yang diciptakan manusia. Bahwa alam juga bisa marah dan balik menyerang manusia melalui hasil dar kerusakan yang manusia ciptakan. Akhirnya, kesadaran pentingnya menjaga lingkungan itu tumbuh karena diri manusia mendapatkan kerugian akibat merusak lingkungan.

Mitos yang terdapat dalam film Diam dan Dengarkan adalah tentang bagaimana mayoritas masyarakat sadar bahwa pentingnya menjaga lingkungan. Aksi nyata menjaga lingkungan tidak cukup jika dilakukan oleh satu atau dua orang. Perlu adanya kolektif bersama untuk menjaga alam sehingga bumi bisa kembali pulih.

Dari interpretasi makna-makna yang terdapat dalam film ini, peneliti menemukan pesan kesadaran lingkungan disampaikan dengan cara memperlihatkan kerusakan lingkungan akibat dari kegiatan manusia sehari-hari yang tidak disadari melalui dialog yang disampaikan oleh narator dan marasumber.

\section{KESIMPULAN DAN IMPLIKASI}

\section{Kesimpulan}

Film dapat digunakan sebagai alat untuk mengkampanyekan kesadaran lingkungan mengingat kondisi alam saat ini dalam keadaan yang sangat memprihatinkan sebagai media massa yang dimudah diterima oleh khalayak,. Seperti yang diperlihatkan melalui makna denotasi, konotasi dan mitos kesadaran lingkungan dalam film dokumenter Diam dan Dengarkan, bahwa kerusakan lingkungan yang terjadi bukan hanya karena penebangan hutan secara liar, polusi oleh kendaraan, atau polusi yang diakibatkan oleh limbah korporasi. Namun dalam film ini, memperlihatkan fakta baru bahwa kerusakan lingkungan terjadi diakibatkan oleh aktivitas manusia seharihari yang tidak disadari.

Dimulai dari keserakahan manusia sejak awal mula penciptaannya yang mana manusia merasa menjadi kasta tertinggi dari segala makhluk hidup di muka bumi ini. Penggunaan plastik yang awalnya bertujuan mengurangi penebangan pohon untuk produksi kantong kertas. Namun malah menjadi polutan baru yang sulit diuraikan. Punic Buying saat pandemi covid-19 yang ternyata dipandang primitif oleh masyarakat pedalaman. Mindset semakin banyak busa yang dihasilkan sabun semakin bersih, nyatanya hanya menghasilkan polusi air. Dan konsumerisme pakaian yang juga ikut andil dalam kerusakan alam ini.

Pesan yang lebih ditonjolkan melalui narasi, dialog, gambar dan video terkait isu lingkungan dalam film ini bertujuan mengajak penonton untuk mengetahui fakta bahwa keseharian manusia yang biasa dilakukan setiap hari ternyata berdampak besar terhadap rusaknya alam. Kemudian pesan-pesan tersebut diartikan sebagai kesadaran lingkungan. Sadar bahwa sebagai manusia harus bijak dalam memilih aktivitas yang akan dilakukannya sehari-hari. Dimulai dari bijak dalam penggunaan plastik, beralih pada peralatan atau produk ramah lingkungan, bahkan dalam kosmetik sekalipun. Lebih sederhana lagi dalam menyikapi penampilan, mengambil seperlunya bahan kebutuhan pokok seharihari tanpa menyimpan sebanyaknya, dan ikut serta dalam perbaikan alam melalui 
energi kolektif dengan bersama-sama menyadari dan bertindak sepenuhnya untuk menjaga alam ini.

\section{Implikasi}

Implikasi dari penelitian ini yaitu media film menghadirkan pemaknaan yang direpresentasikan melalui adegan, dialog, narasi serta pengambilan gambar sehingga dapat menjadi alternatif dalam peyebaran pesan atau informasi. Dapat dilihat melalui pesan kesadaran lingkungan dalam film dokumenter Diam dan Dengarkan yang diteliti dalam penelitian ini menambah informasi mengenai dampak kerusakan lingkungan diakibatkan oleh aktivitas kegiatan manusia sehari-hari yang tidak disadari. Diharapkan dari penelitian ini, akan semakin memperluas pengetahuan dan informasi mengenai studi semiotika khususnya dalam komunikasi lingkungan. Setelah melakukan penelitian pada film Diam dan Dengarkan terkait pemaknaan pesan kesadaran lingkungan, peneliti memberikan arahan bagaimana pesanpesan kesadaran lingkungan :

1. Peneliti mengharapkan dunia film mampu memberikan informasi mengenai pentingnya menjaga lingkungan di tengah krisis iklim ini.

2. Sebaiknya khalayak secara perlahan dan konsisten merubah gaya hidup yang merusak ke arah gaya hidup ecofriendly atau ramah lingkungan.

3. Sebaiknya untuk lebih mengkaji mengenai topik kesadaran lingkungan yang lebih kompleks melalui media lain. Tujuannya untuk melihat sudut pandang lain mengenai kesadaran lingkungan yang disampaikan melalui media lain, seperti lagu atau musik.

\section{DAFTAR PUSTAKA}

Bungin, Burhan. 2006. Sosiologi Komunikasi. Edisi Pertama. PT Kencana Prenadamedia Group. Jakarta
Film Diam dan Dengarkan. 2020. https://www.youtube.com/watch?v=Nv NLumlAJX0

Ghony, Djunaidi M. Almanshur, Fauzan. 2016. Metode Penelitian Kualitatif. Edisi Ketiga. Ar-Ruzz Media. Yogyakarta

Halik, Abdul. 2018. Paradigma Kritik Penelitian Komunikasi (Pendekatan Kritis-Emansipatoris dan Metode Etnografi Kritis. Jurnal Tabligh. 19 (2): 162-178

Littlejhon, W. Stephen, A.Foss, Karen. 2018. Teori Komunikasi. Edisi Sembilan. Salemba Humantika. Jakarta

Merdeka, D. K. Moyang. 2020. Kita Selalu Menyalahkan Sistem. Majalah Tempo Digital Edisi 18 Juli 2020. Diakses 21 Januari 2021 melalui https://majalah.tempo.co/read/selingan /160942/wawancara-mahatma-putrasutradara-film-diam-dengarkan-kitatelah-mengorbankan-bumi.

Murfianti, Fitri. 2020. Sexy Killer : Film and Enviromental Movement. Capture : Jurnal Seni Media Rekam. 12 (1): 48-62

Neolaka, A. 2008. Kesadaran Lingkungan. Edisi Pertama. Jakarta. PT Rineka Cipta

Sobur, Alex. 2013. Semiotika Komunikasi. Edisi Kelima. Remaja Rosdakarya. Bandung

Sobur, Alex. 2006. Analisis Teks Media Suatu Pengantar untuk Analisa Wacana, Analisis Semiotik, dan Analisis framing. Edisi Keduabelas. PT Remaja Rosdakarya. Bandung

Sugiyono. 2014. Metode Penelitian Kuantitaif, Kualitatif, dan R\&D. Edisi Cetakan Ketujuh. PT Remaja Rosdakarya. Bandung

Schlegelmilch, B. B., Diamantopoulos, A., \& Bohlen, G. M. 1996. The link between green purchasing decisions and measures of environmental consciousness. European Journal of Marketing, 30(5). 35-55.

Vera, Nawiroh. 2014. Semiotika dalam Riset Komunikasi. Edisi Pertama. Ghalia Indonesia. Bogor. 